\title{
Increased expression of humanin peptide in diffuse- type pigmented villonodular synovitis: implication of its mitochondrial abnormality
}

\author{
K liiri, H Tsuruga, H Sakakima, K Tomita, N Taniguchi, K Shimoonoda, S Komiya, \\ M B Goldring, H J Majima, T Matsuyama
}

See end of article for authors' affiliations

Correspondence to: Dr K liji, Beth Israel Deaconess Medical Center, Harvard Institutes of Medicine, Room 237, 4 Blackfan, Circle, Boston, MA 02115, USA; kiïiri@ bidmc.harvard.edu

Accepted 27 October 2004 Published Online First 26 November 2004
Objectives: To define the pathogenesis of pigmented villonodular synovitis (PVNS), by searching for highly expressed genes in primary synovial cells from patients with PVNS.

Methods: A combination of subtraction cloning and Southern colony hybridisation was used to detect highly expressed genes in PVNS in comparison with rheumatoid synovial cells. Northern hybridisation was performed to confirm the differential expression of the humanin gene in PVNS. Expression of the humanin peptide was analysed by western blotting and immunohistochemistry. Electron microscopic immunohistochemistry was performed to investigate the distribution of this peptide within the cell.

Results: 68 highly expressed genes were identified in PVNS. Humanin genes were strongly expressed in diffuse-type PVNS, but were barely detected in nodular-type PVNS, rheumatoid arthritis, or osteoarthritis. Humanin peptide was identified in synovium from diffuse-type PVNS, and most of the positive cells were distributed in the deep layer of the synovial tissue. Double staining with anti-humanin and anti-heat shock protein 60 showed that humanin was expressed mainly in mitochondria. Electron microscopy disclosed immunolocalisation of this peptide, predominantly around dense iron deposits within the siderosome.

Conclusions: Increased expression of the humanin peptide in mitochondria and siderosomes is characteristic of synovial cells from diffuse-type PVNS. Humanin is an anti-apoptotic peptide which is encoded in the mitochondrial genome. Present findings suggest that mitochondrial dysfunction may be the principal factor in pathogenesis of diffuse-type PVNS and that humanin peptide may play a part in the neoplastic process in this form of PVNS.
$\mathrm{P}$ gmented villonodular synovitis (PVNS) is classified as an uncommon idiopathic proliferative synovial process. ${ }^{12}$ It can exist in a localised form within a joint but more commonly occurs as a diffuse form where the entire synovium of a joint is affected..$^{3-7}$ The exact aetiology of PVNS is still unknown. ${ }^{8-10}$ Previous experimental and epidemiological studies have suggested that PVNS is a reactive process involving a chronic inflammatory response. ${ }^{11}{ }^{12}$ However, recent studies showing the capacity of these lesions for autonomous growth and the potential for recurrence have suggested involvement of a neoplastic process. ${ }^{13}$ The neoplastic hypothesis has been further supported by studies suggesting that heterogeneous proliferating cells, such as fibroblasts, histiocytes, multinuclear cells, and chronic inflammatory cells, might be neoplastic, with other cell types being reactive in nature. ${ }^{14} 15$

Histologically, PVNS is composed of proliferating mononuclear cells, with frequent giant cells, and intracellular and extracellular iron deposits. These iron deposits are observed as membrane bound particles in siderosomes. Interestingly, Schumacher et al and Ghadially et al reported that the siderosome fuses with mitochondria in deep synovial cells from patients with PVNS. ${ }^{16}{ }^{17}$ Moreover, abundant mitochondria throughout the cytoplasm were observed in dispersed stromal cells containing electron dense inclusions and in giant cells. ${ }^{16} 18$

In this study we searched for highly expressed genes in primary synovial cells from patients with PVNS compared with those from patients with rheumatoid arthritis (RA). We considered that a comparison of synovial cells from PVNS with those from RA, which are composed of chronic inflammatory cells, would identify the distinct nature of PVNS and define this proliferative process more precisely. Ribosomal RNA (rRNA) with poly A tail encoded by mitochondrial genes was highly expressed in PVNS. Among these genes, humanin has been reported to act as an oncopeptide or as an anti-apoptotic factor against Bax (Bcl2 associated $\mathrm{X}$ protein), which is an apoptosis-inducing protein. ${ }^{19}{ }^{20}$ However, little is known about the pathological role of humanin in diseases other than Alzheimer's disease.

We report here that the expression of humanin peptide is increased strongly in diffuse-type PVNS compared with other arthritides and it is abundant in mitochondria and siderosomes of synovial cells from PVNS.

\section{METHODS}

Synovial tissue preparation and RNA extraction

Synovial biopsy specimens were obtained during surgery from six patients with PVNS, three with RA, and three with osteoarthritis (OA). These lesions were subtyped into two types (diffuse or nodular) according to locations (intraarticular versus extra-articular) and pathological growth patterns, which reflected clinical characteristics and biological behaviour. ${ }^{13}$

\footnotetext{
Abbreviations: BSA, bovine serum albumin; GAPDH, glyceraldehyde3-phosphate dehydrogenase; hsp, heat shock protein; IMDM, Iscove modified Dulbecco's medium; OA, osteoarthritis; PBS, phosphate buffered saline; PCR, polymerase chain reaction; PVNS, pigmented villonodular synovitis; RA, rheumatoid arthritis; RT-PCR, reverse transcriptase-polymerase chain reaction; SDS, sodium dodecyl sulphate; SDS-PAGE, sodium dodecyl sulphate-polyacrylamide gel electrophoresis; SSC, saline sodium citrate
} 
The patients with RA met the criteria of the 1987 American College of Rheumatology. The tissue was cultured in Iscove modified Dulbecco's medium (IMDM) with collagenase V ( $1 \mathrm{mg} / \mathrm{ml}$ medium) for 40 minutes and cells were harvested through mesh and gathered by centrifugation. Total cellular RNA was extracted using acid-guanidinium-phenol-chloroform (AGPC) methods. ${ }^{21}$ Equal aliquots were then electrophoresed on $1 \%$ agarose gels stained with ethidium bromide to compare large and small rRNA qualitatively and to exclude degradation. Poly $\mathrm{A}^{+}$RNA was purified from total RNA using the First Track kit (Invitrogen).

\section{Double stranded cDNA synthesis and subtraction cloning}

One microgram of total RNA sample was used to synthesise full length, double stranded cDNA using a SMART polymerase chain reaction (PCR) cDNA synthesis kit (Clontech). Subtraction cloning was performed with a PCR-Select cDNA subtraction kit (Clontech). Equal amounts of double stranded cDNAs from two patients with PVNS (diffuse type/lane 1, nodular type/lane 2 in fig 2) were used as tester cDNAs, and equal amounts of double stranded cDNAs from three patients with RA were used as driver cDNAs. PCR using CD163 primers was performed to estimate the efficiency of subtraction, and the expected decrease in CDl63 in the subtracted sample was observed (data not shown).

\section{Southern colony hybridisation}

Subtracted cDNAs were ligated to TOPO vector (Invitrogen) and transformed into DH10B cells (Invitrogen) by electroporation. After blue-white selection with X-gal containing Luria-Bertani (LB) plates, white colonies were cultured overnight with $150 \mu \mathrm{l} \mathrm{LB}$ medium in sterile $1.5 \mathrm{ml}$ tubes and centrifuged for 2 minutes at $12000 \mathrm{~g}$, and the pellet was

Table 1 Highly expressed genes in PVNS compared with RA

\begin{tabular}{lc}
\hline Genes & No \\
\hline Mitochondrial & 30 \\
16S rRNA & 5 \\
12S rRNA & 2 \\
Homosapiens tomoregulin mRNA & 1 \\
Homosapiens ARFGAP 1 protein mRNA & 1 \\
Mitochondrial proteolipid 68 MP homology & \\
& \\
Inflammation & \\
$\beta_{2}-$ Microglobulin mRNA & 4 \\
Transforming growth factor- $\beta$ mRNA & 1 \\
Fibrogenolysis & \\
Arg/serpin 1 plasminogen activator-inhibitor 2 mRNA & 1 \\
Homosapiens similar to serine proteinase mRNA & 1 \\
Homosapiens similar to serine/arginine repetitive matrix \\
mRNA
\end{tabular}

resuspended in $10 \mu \mathrm{l} \mathrm{LB}$ medium. The medium was mixed completely and $2 \mu \mathrm{l}$ was dotted onto a nylon membrane for Southern hybridisation. SMART double stranded CDNA was labelled with $\left[{ }^{32} \mathrm{P}\right] \mathrm{dCTP}$ by random priming (Stratagene). Membranes were hybridised in aqueous solution $(5 \times$ saline sodium citrate (SSC), Denhardt's solution, $0.1 \%$ sodium dodecyl sulphate (SDS), $10 \mathrm{mg}$ salmon sperm DNA) overnight at $65^{\circ} \mathrm{C}$. After washing at $65^{\circ} \mathrm{C}$ for 1 hour in $0.1 \times$ SSC, $0.1 \%$ SDS, the membranes were exposed to $x$ ray film (Eastman Kodak Co) with an intensifying screen at $-80^{\circ} \mathrm{C}$. Measurement of cDNA was performed by scanning with a BASS 1000 Densitometer (Fuji film), and normalisation against glyceraldehyde-3-phosphate dehydrogenase (GAPDH) cDNA hybridised subsequently on the same blots.

\section{DNA sequencing}

Sixty eight cDNAs from differentially expressed clones were amplified with M13 reverse (5' -CAGGAAACAGCTATGAC-3') primers using thermal cycling conditions $\left(96^{\circ} \mathrm{C}\right.$ for $30 \mathrm{sec}-$ onds, $50^{\circ} \mathrm{C}$ for 15 seconds, $60^{\circ} \mathrm{C}$ for 4 minutes for 25 cycles). The cDNAs were purified and sequenced using the ABI PRISM dye terminator cycle sequencing ready reaction kit with template suppression reagent (ABI PRISM). DNA sequences were analysed using DNASIS software and compared with sequences in GeneBank (National Center for Biotechnology Information, Bethesda, MD).

\section{Northern hybridisation}

Poly $\mathrm{A}^{+}$RNA (168 ng) samples of the synovium from five patients with PVNS, three with RA, and three with OA patients were loaded and fractionated through $1.0 \%$ agarose gels and transferred to Hybond-N+ nylon transfer membrane (Amersham). Purified human cDNA (40 ng) was labelled with $\left[{ }^{32} \mathrm{P}\right] \mathrm{dCTP}$ by random priming and applied to the membrane for hybridisation in aqueous solution $(5 \times$ SCC, Denhardt's solution, $0.1 \%$ SDS, $10 \mathrm{mg}$ salmon sperm DNA, $50 \%$ formamide) overnight at $42^{\circ} \mathrm{C}$. After washing at $42^{\circ} \mathrm{C}$ for 1 hour in $0.1 \times$ SSC, $0.1 \%$ SDS, the membranes were exposed to $x$ ray film (Eastman Kodak Co) with an intensifying screen at $-80^{\circ} \mathrm{C}$.

\section{Semiquantitative reverse transcriptase-polymerase chain reaction ( $R T-P C R$ )}

Total RNA $(2.5 \mu \mathrm{g})$ from five patients with PVNS, three with RA, and two with OA was used for cDNA synthesis with oligo(dT) ${ }_{12-18}$ as template primer using M-MuLV reverse transcriptase. The reaction was conducted in a final volume of $50 \mu \mathrm{l}$ containing $1 \mathrm{ml}$ of the transcribed cDNA probe, $200 \mu \mathrm{mol} / \mathrm{l}$ of each dNTP, $1 \times$ PCR buffer including $1.5 \mathrm{mM}$ $\mathrm{MgCl}_{2}$ (Takara Biomedical), $0.4 \mu \mathrm{M}$ forward and reverse primers, and $2.5 \mathrm{U}$ Taq polymerase (Takara). All amplimers were amplified simultaneously with GAPDH as internal standard. The respective primer pairs were for cytochrome $c$ (forward: 5'-GCATAAACAACATAAGCTTCTGA-3', reverse: 5'-CAGCAGATCATTTCATATTGCTT-3'), for ATPase (forward: 5'-TCTCATCAACAACCGACTAATCA-3', reverse: 5' GATAAGTGTAGAGGGAAGGTTAA-3'), for NADH dehydrogenase (forward: 5'-TTTACTCAATCCTCTGATCAGGG-3', reverse: 5'-CGAATTCATAAGAACAGGGAGGT-3'), and for cytochrome $b$ (forward: 5' -AATTACAAACTTACTATCCGCCA3', reverse: 5'-TGGGCGAAATATTATGCTTTGTT-3'). The reaction mixtures were incubated for 3 minutes at $94^{\circ} \mathrm{C}$, followed by 32 cycles of denaturation for 1 minute at $94^{\circ} \mathrm{C}$, annealing for 1.5 minutes at $52^{\circ} \mathrm{C}$, and extension for 1 minute at $72^{\circ} \mathrm{C}$.

\section{Cell and tissue processing for light microscopy and immunohistochemistry}

To isolate synovial cells, the deep layers of synovium from diffuse-type PVNS were cultured in IMDM with collagenase 


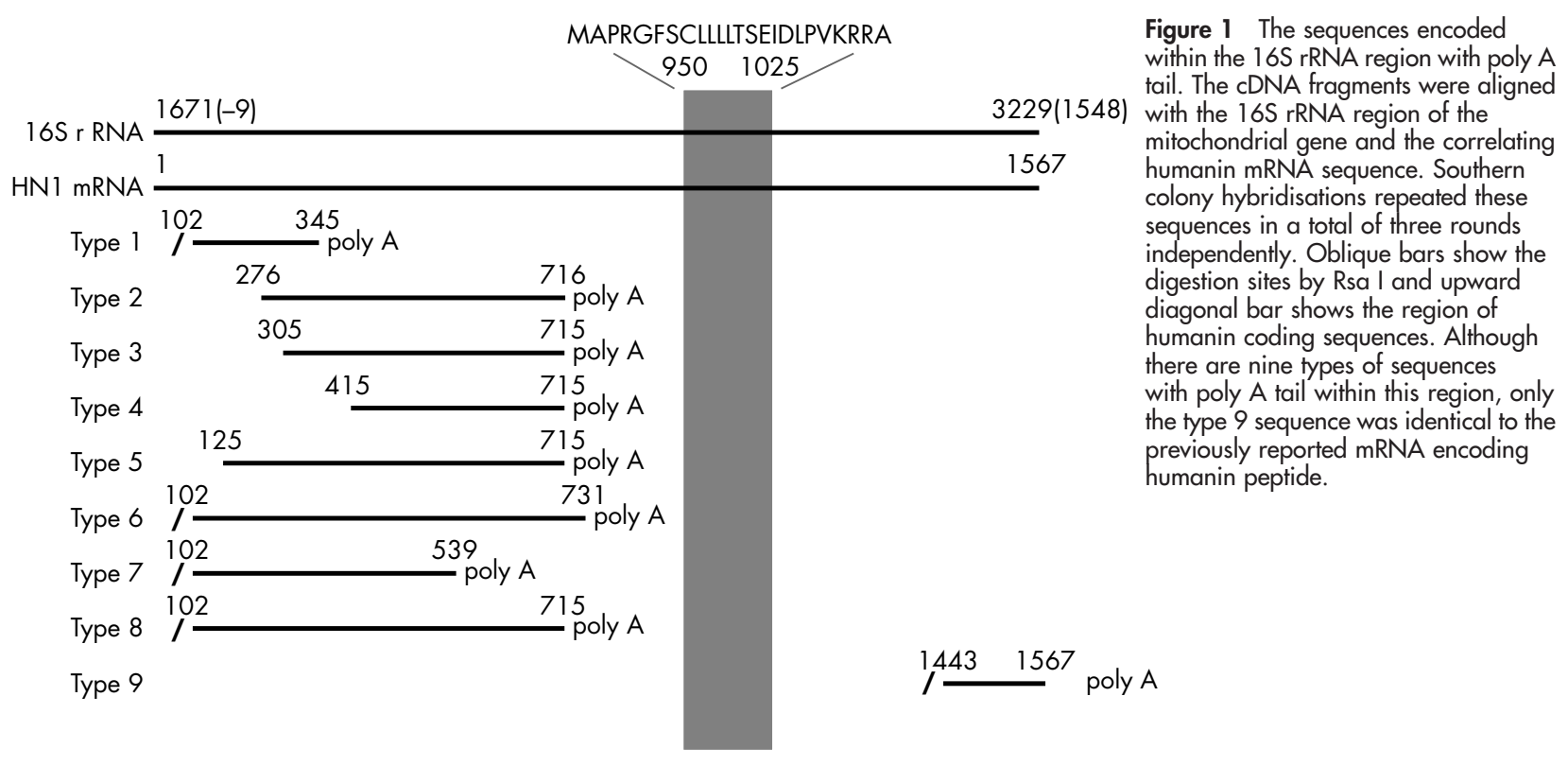

V ( $1 \mathrm{mg} / \mathrm{ml}$ medium) for 20 minutes and cells were harvested through mesh and gathered by centrifugation. These synovial cells were cultured in IMDM with $10 \%$ fetal bovine saline for 4 hours and fixed with $10 \%$ buffered formaldehyde at room temperature for 10 minutes, then rinsed with phosphate buffered saline (PBS). Formalin fixed tissue sections were also used for immunostaining. A rabbit polyclonal anti-humanin antibody was synthesised and purified on an affinity column and dissolved in PBS $(0.9 \%$ $\mathrm{NaCl}, 0.02 \mathrm{M}$ phosphate buffer, $\mathrm{pH}$ 7.0). The IgG concentration was analysed using a protein assay kit (Bio-Rad). Immunostaining was performed as previously described. ${ }^{22}{ }^{23}$ Briefly, cells and sections were fixed with $4 \%$ formaldehyde in PBS. After rinsing with PBS, membrane perforation treatment was performed with $95 \%$ ethanol/5\% acetic acid for 10 minutes. After washing with PBS and blocking by incubation with $1 \%$ bovine serum albumin (BSA), excess BSA was then removed and the cells were incubated with anti-humanin antibodies overnight at $4^{\circ} \mathrm{C}$. After rinsing, Alexa Fluor 488 goat antirabbit IgG (Molecular Probes Inc) was applied as a secondary antibody for 60 minutes. Immunofluorescence was detected with a CSU-10 confocal laser scanning unit (Yokogawa Electric Co), coupled to an IX90 inverted microscope with UPlanAPOX20 objective lens (Olympus Potical Co), and C5810-01 colour chilled 3CCD camera (Hamamatsu Photonics, KK). For double staining, anti-humanin antibody and anti-heat shock protein (hsp) 60 antibody (Santa Cruz Biochemistry Inc) were used as first antibodies, while Alexa Fluor 568 goat antirabbit IgG and Alexa Fluor 488 donkey antigoat IgG (Molecular Probes Inc) were used as a second antibodies.

\section{Western blot analysis}

Tissues were homogenised and lysed in a buffer consisting of $150 \mathrm{mM} \mathrm{NaCl}, 50 \mathrm{mM}$ Tris $\mathrm{HCl}, \mathrm{pH} 7.5,0.5 \%$ Nonidet 40 , $50 \mathrm{mM} \mathrm{NaF}, 1 \mathrm{mM} \mathrm{Na} \mathrm{VO}_{4}, 1 \mathrm{mM}$ phenylmethylsulphonyl fluoride, and $1 \%$ aprotinin at $4{ }^{\circ} \mathrm{C}$ for 30 minutes. Cell lysates were cleared of cell debris by centrifugation at $14000 \mathrm{~g}$ for 30 minutes. Protein $(20 \mu \mathrm{g})$ was subjected to sodium dodecyl sulphate-polyacrylamide gel electrophoresis (SDS-PAGE) on

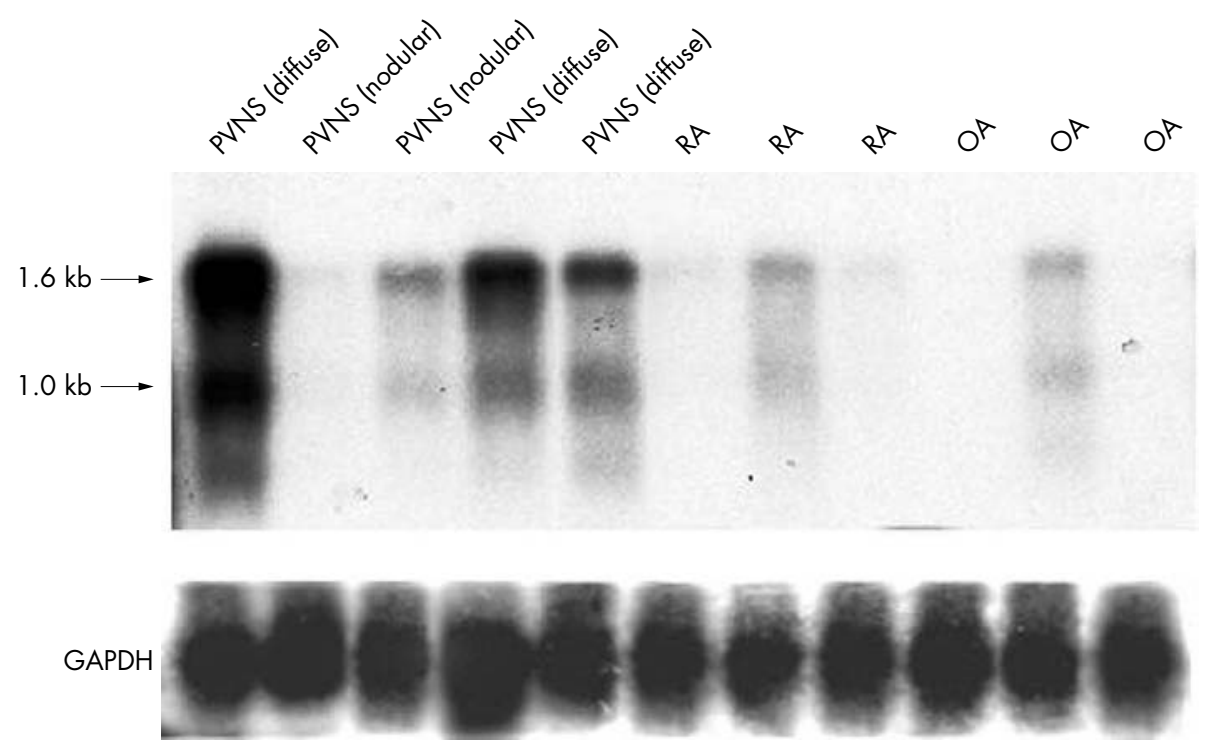

Figure 2 Northern blot analysis of mRNAs expressed by synovial cells from patients with PVNS, RA, and OA. Total RNA (168 $\mathrm{ng}$ ) was subjected to electrophoresis in a $1.0 \%$ agarose gel containing formaldehyde, transferred to a nylon membrane, and probed with [ ${ }^{32}$ P]dCTP labelled cDNA (type 9; fig 1). Another CDNA (type 3) encoded in the $16 \mathrm{~S}$ rRNA region was also used in northern blotting and the expression level and size were same as those using type 9 cDNA (data not shown). Humanin genes were strongly expressed in diffuse-type PVNS, but barely detected in nodular-type PVNS, RA, or OA. The size of the expressed major message was $\sim 1.6 \mathrm{~kb}$ and the other messages were $\sim 1 \mathrm{~kb}$, which corresponds to the results of a previous report by Hashimoto et al. ${ }^{28}$ 

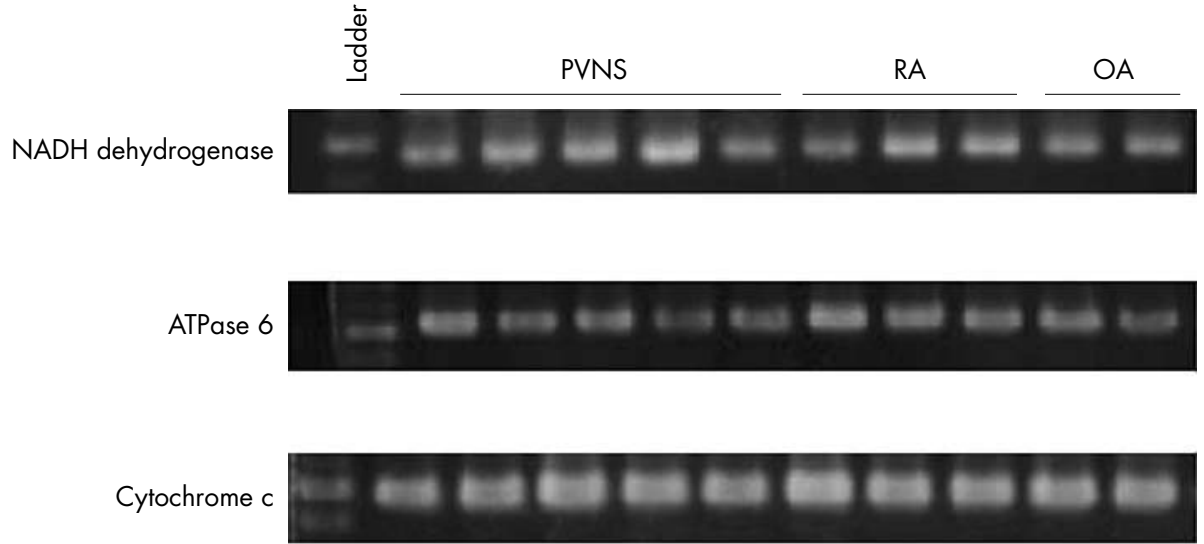

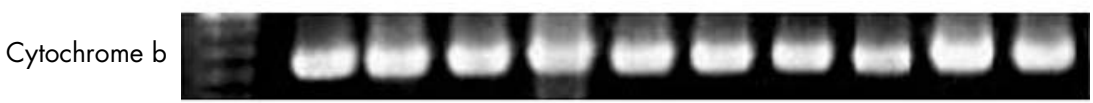

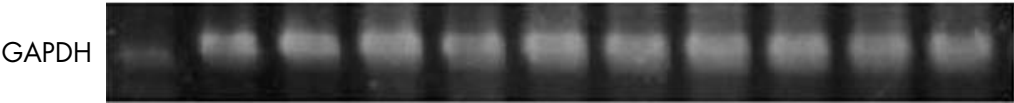

Figure 3 The expression of genes encoded in mitochondria other than humanin genes. Total RNA was

extracted from the synovial cells of five patients with PVNS, three with RA, and three with OA, and NADH

dehydrogenase, ATPase 6, cytochrome $c$, cytochrome $b$, and GAPDH mRNA levels were analysed by

semiquantitative RT-PCR. The levels of expression of these genes in PVNS were not increased in other types of arthritis, indicating that the humanin gene was selectively expressed in mitochondrial genes in PVNS. a PAG mini Daiichi 15/25 gel (Daiichi Pure Chemical Co). The gel electrophoresis was performed under non-reducing conditions. The proteins were then blotted onto a nitrocellulose blotting membrane (Osmonics Inc). Nitrocellulose membranes were blocked with 5\% BSA, followed by washing with PBS-Tween 20, and incubated with rabbit anti-humanin antibody at $4^{\circ} \mathrm{C}$ overnight. After intensive washing, membranes were incubated with horseradish peroxidase linked goat antirabbit IgG, followed by detection with enhanced chemiluminescence reagents (Biotechs).

\section{Electron microscope and colloidal gold immunocytochemistry}

Synovial cells from diffuse-type PVNS were gathered in the same manner for light microscopy, and fixed in $3 \%$ glutaraldehyde in $0.1 \mathrm{M}$ phosphate buffer $(\mathrm{pH} 7.4)$ at $4{ }^{\circ} \mathrm{C}$ over night. The specimens were postfixed in $1 \% \mathrm{OsO}_{4}$ in $0.1 \mathrm{M}$ phosphate buffer ( $\mathrm{pH} 7.4$ ) overnight at $4^{\circ} \mathrm{C}$, rinsed three times (10 minutes each) in 10\% saccharose, and stained all together in 3\% aqueous uranyl acetate for 1 hour at room temperature. Samples were then dehydrated in an ascending series of ethanol concentrations, replaced by

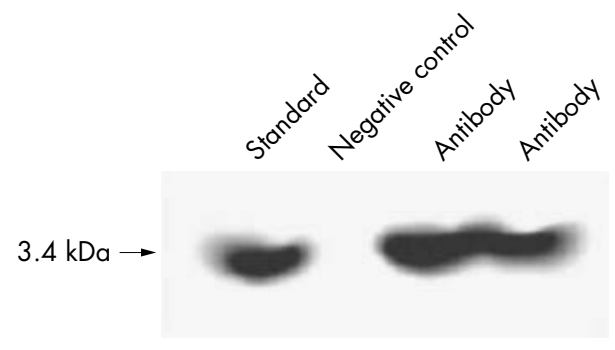

Figure 4 Expression of humanin peptide in synovial cells from diffusetype PVNS. Protein $(20 \mu \mathrm{g})$ from synovial cell lysates was subjected to SDS-PAGE on a 5-20\% gradient gel. Rabbit anti-humanin polyclonal antibody was used for western blotting. Synthesised peptide, which was used as antigen to produce rabbit anti-humanin polyclonal antibody, was used as a standard and rabbit lgG was used as a negative control. propylene oxide, and embedded in epoxy resin. Ultrathin sections $(100 \mathrm{~nm})$ were cut, stained with uranyl acetate and lead citrate, and observed using an electron microscope (Hitachi H-7000).

For electron microscopic immunocytochemistry, cells were fixed in $0.2 \%$ glutaraldehyde and $4 \%$ paraformaldehyde mixture in $0.1 \mathrm{M}$ phosphate buffer $(\mathrm{pH} 7.4)$ at $4^{\circ} \mathrm{C}$ overnight. The samples were embedded into Lowicryl K4M, and ultrathin sections $(100 \mathrm{~nm})$ were used for incubation with anti-humanin antibody overnight. Incubation with the biotinylated secondary antibody was performed at room temperature for 1 hour, and after washing with PBS and distilled water, incubation with colloidal gold streptavidin was performed for 1 hour. The sections were rinsed and dried, then stained with uranyl acetate and lead citrate, and electron microscopy was performed as described above.

\section{RESULTS}

\section{Identification of highly expressed genes in PVNS}

A total of 2956 clones selected by subtraction cloning were further examined by Southern colony hybridisation. The sequencing was performed on genes expressed in PVNS at three times greater frequency than those in RA. Sixty eight of the highly expressed genes were identical to 17 known genes. Two genes were identical to genes encoding two hypothetical proteins. Table 1 classifies these genes into seven groups according to their functions and whether they were transcribed in mitochondria. Interestingly, genes encoded in the region of 16S rRNA and 12S rRNA were expressed with high frequencies. Furthermore, we detected various forms of 16S rRNA with poly A tail end, as shown in fig 1. No 12S rRNA with poly A tail was found among these genes. The cDNA with poly A tail (16S rRNA•3229: type 9 in fig 1) was identical to the humanin gene.

Northern blot analysis was performed using mRNA of synovial cells from patients with PVNS, RA, and OA. Humanin genes were strongly expressed in diffuse-type PVNS, but were barely detectable in nodular-type PVNS, RA, or OA (fig 2). However, other genes encoded by mitochondria were not increased as assessed by semiquantitative RT-PCR, suggesting 


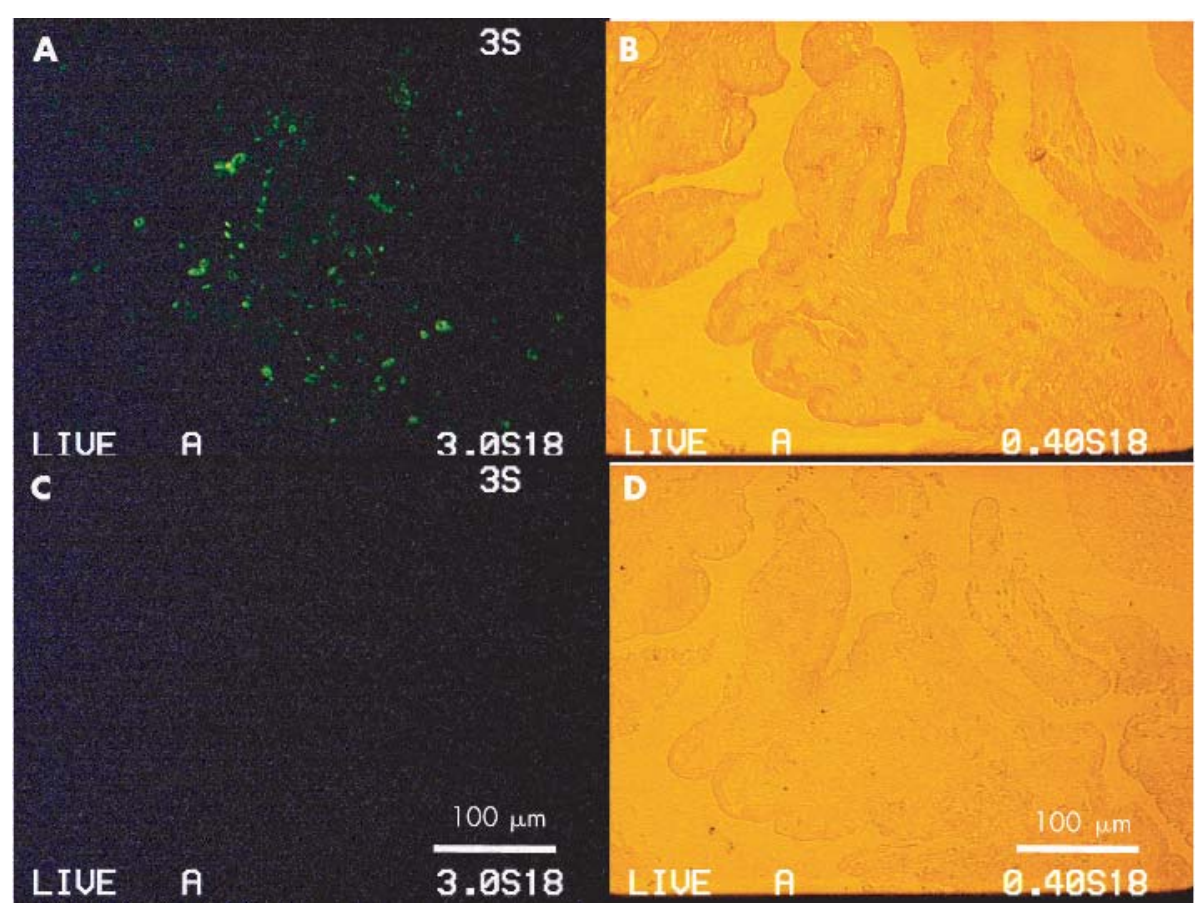

Figure 5 Synovial tissue from diffuse-type PVNS was fixed with $4 \%$ formaldehyde in PBS. The specimens were stained with anti-humanin antibody, followed by Alexa 488 goat antirabbit lgG, and photographed with a fluorescent microscope $(\times 40)$. (A) Most positive cells (green) were distributed in a deep layer with haemosiderin deposit. (C) Negative control of the continuous section. (B, D) Backgrounds for (A) or (C), respectively.

that ribosomal genes were selectively expressed in mitochondrial genes in PVNS (fig 3). As far as we know, this is the first report of the expression of the humanin gene in synovial cells.

\section{Expression of the humanin peptide in PVNS}

Next, the expression of humanin peptide was identified using synovial cell lysates from diffuse-type PVNS and antihumanin polyclonal antibody (fig 4). Immunohistochemical analysis showed that most of the positive cells were distributed in the deep layer (fig 5). This positive staining was thoroughly suppressed by blocking the primary antibody with synthesised antigen peptide (data not shown).

Although it has been suggested that the humanin peptide is expressed by cells in the deep layer of PVNS, little is known about the intracellular localisation of this peptide. In further examinations, we detected intracellular humanin peptide in synovial cells from diffuse-type PVNS. The humanin peptide was stained with a red colour, which localised in the cytoplasm of the synovial cells (fig 6B) but not in the nucleus. Mitochondria were stained with a green colour using anti-hsp60, which is mitochondrial-specific chaperonin (fig 6C). Double staining with anti-humanin antibody and anti-hsp60 (yellow colour) demonstrated that humanin was expressed mainly in the mitochondria (fig 6D).

Electron microscopic observation of synovial cells from diffuse-type PVNS showed that most of the iron deposits were included within the siderosome as described previously. ${ }^{16}{ }^{17}$ However, some electron dense iron deposits were
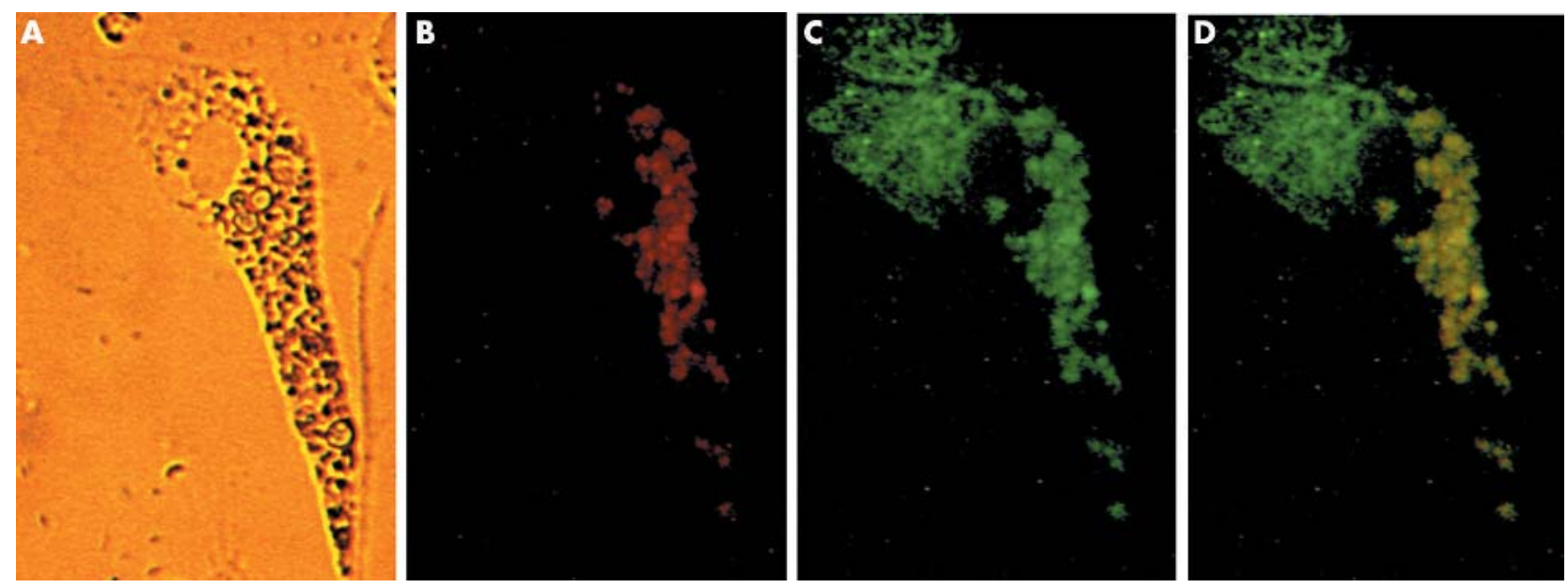

Figure 6 Relationship between humanin peptide expression and mitochondria. Isolated synovial cells containing haemosiderin were double stained with anti-humanin antibody and anti hsp60 antibody as first antibodies, followed by goat antirabbit lgG and donkey antigoat lgG as second antibodies $(\times 400)$. (A) Haemosiderin was deposited unequally throughout the cytoplasm. (B) Single anti-humanin antibody staining (red). (C) Single anti-hsp60 antibody staining (mitochondrial staining; green). (D) Humanin was dominantly distributed in the mitochondria around the siderosome (yellow). 


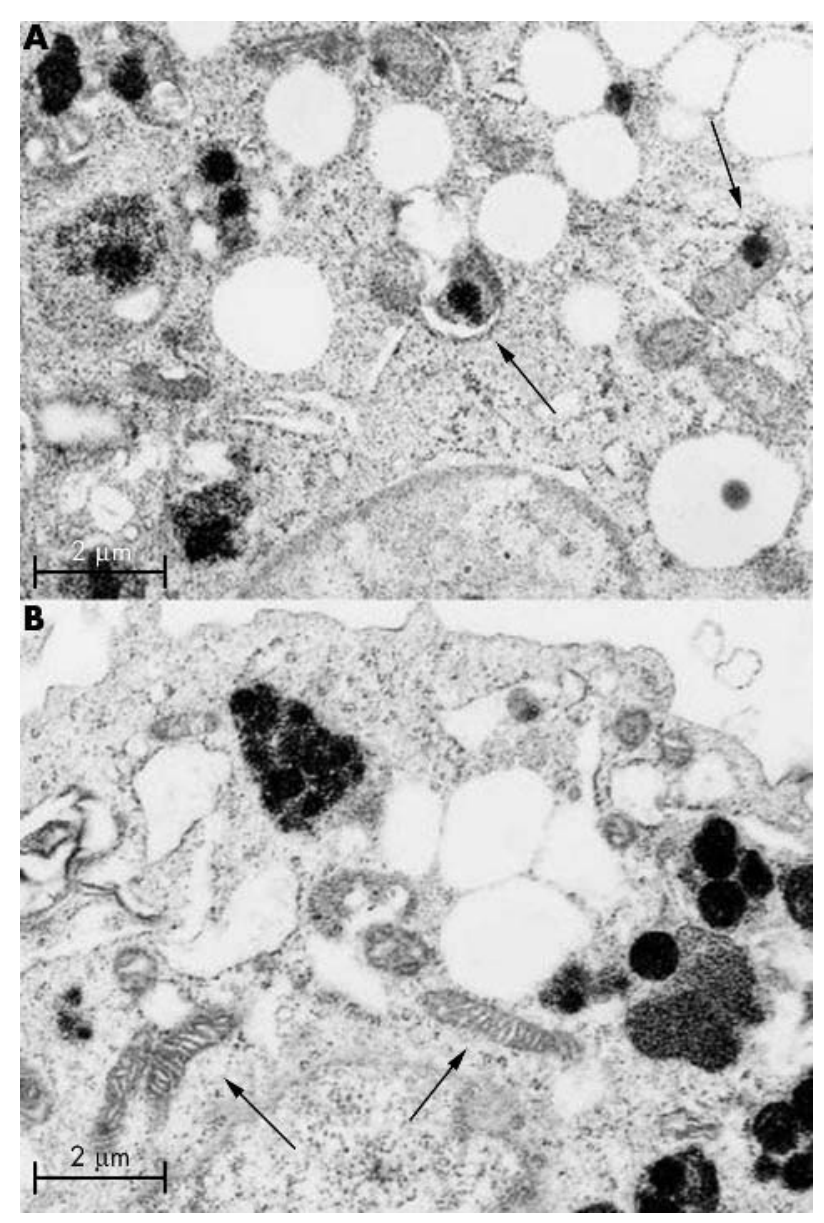

Figure 7 Electron micrograph of synovial cells from diffuse-type PVNS Most of the electron dense iron deposits were observed within the siderosomes. Some electron dense iron deposits were observed within mitochondria (arrows). (A) Mitochondrial membrane debris with electron dense deposits was observed within the siderosome as an autophagosome (left arrow). (B) Some of the normal mitochondria (arrows) also were scattered throughout the cytoplasm. (Magnification $\times 19000$.)

observed within the mitochondria (fig 7A). Interestingly, mitochondrial membrane debris with electron dense iron deposits were observed within the siderosome, which was characterised as an autophagosome (fig 7A). On the other hand, some normal mitochondria were scattered throughout the cytoplasm (fig 7B). Electron dense iron deposits within the siderosome were observed by electron microscopic immunohistochemistry (fig 8). In some siderosomes, particles of colloidal gold were precipitated in the debris adjacent to electron dense iron (fig 8A). These results suggest that humanin exists in mitochondria not only in the cytoplasm but also in the siderosome after being phagocytosed.

\section{DISCUSSION}

Genes with enhanced expression in synovial cells from PVNS were grouped according to their functions and the transcription in mitochondria as listed in table 1. It is likely that many of the listed genes play a part in the pathogenesis of PVNS according to their characterised functions. Interestingly, genes encoded in the regions of 16S rRNA and 12S rRNA were expressed with high frequencies. Previous reports pointed out the presence of polyadenylated transcripts of the 16S rRNA gene that differed from the 16S rRNA. ${ }^{24-26}$ These poly A sequences are considered to be due to active metabolism of mitochondria in cancer cells, because the
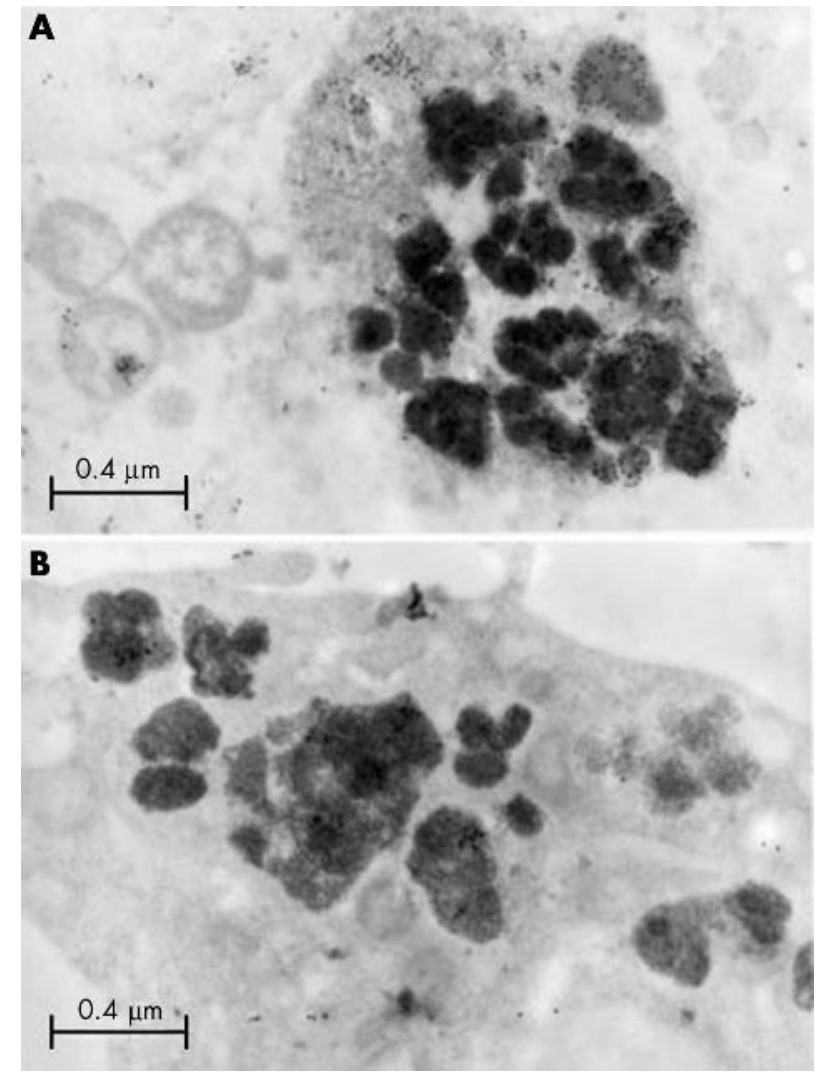

Figure 8 Electron microscopic immunohistochemistry of synovial cells from diffuse-type PVNS. (A) In some of the siderosomes, particles of colloidal gold, were precipitated in the debris adjacent to electron dense iron. These results demonstrate that humanin peptide is present within the debris that is phagocytosed into the siderosome. (B) Negative control for immunohistochemistry. (Magnification $\times 29000$.)

increased expression of the 16S rRNA genes was found only in malignancies. ${ }^{19} 27$ These facts suggest that the genes encoded in the region of rRNA from PVNS reflect the neoplastic nature of this disease. In fact, for PVNS, especially the diffuse type, the neoplastic hypothesis is supported by the demonstration of aneuploid DNA content and the existence of cytogenetic aberration, as well as the capacity of these lesions for autonomous growth and the potential for recurrence. ${ }^{13} 14$

It is intriguing to examine whether these mitochondrial genes for $16 \mathrm{~S}$ rRNA are virtually translated and act as functional peptides. In this regard, humanin is a polypeptide described as a rescue factor abolishing neural cell apoptosis. This peptide protects neural cells of the Fll line from death induced by the expression of mutated genes, causing early onset familiar Alzheimer's disease. ${ }^{28}$ Additionally, it was reported that humanin protects $\mathrm{CN}$-procaspase-3 from amyloid precursor protein-induced cleavage, thereby preventing apoptosis. ${ }^{29-31}$ More recently, Guo et al also described the anti-apoptotic mechanism of this peptide through interference with Bax activation..$^{20}$ In this study we proved that the humanin peptide, encoded in the mitochondrial genome, was selectively expressed in the mitochondria and within the siderosome in the diffuse-type PVNS synovial cells. It is well established that damaged and functionally disabled mitochondria may be autophagocytosed by lysosomes to prevent continuous oxidative damage, as shown in the degenerating mitochondria within the siderosome in our electron microscopic study. ${ }^{32}{ }^{33}$ This evidence suggests that humanin is translated in mitochondria, leading to survival of 
this organelle under the condition of excessive iron deposition.

In fact, extreme iron deposition is one of the most characteristic pathological features in PVNS. ${ }^{278}$ This deposit is derived from the breakdown of erythrocytes that are phagocytosed after repeated bleeding into the joint space. ${ }^{163435}$ Under the condition of iron excess, some of the iron is shunted into haemosiderin and stored in the cytoplasm. ${ }^{36}$ It is well described that reactive oxygen species are generated by excessive iron-induced cell apoptosis, which is one important mechanism implicated in the mitochondrial death pathway. ${ }^{36-40}$ This mechanism may involve the capacity of excessive iron deposits to stimulate lipid peroxidation, thereby disrupting lysosomal membranes and releasing tissue destructive hydrolytic enzymes. ${ }^{41}{ }^{42}$ In regard to PVNS, as shown in our subtraction cloning, the iron deposits are known to be associated with large quantities of ferritin. Nevertheless, homogeneous synovial cells with small, rounded siderosomes in the deep layer of synovium, which present predominantly in diffuse-type PVNS, were reported to have minimum tissue damage adjacent to the iron deposits. ${ }^{43}$ Morris et al reported that electron dense iron deposits were associated with mitochondrial destruction in haemophilic synovitis but much less so in PVNS. ${ }^{43}$ Several explanations were suggested for this lack of mitochondrial damage in previous reports, such as transitional function during inflammation, or the failure of the apoferritin response. ${ }^{31}{ }^{43}$ However, there were no facts to explain this pathology.

The alternative intriguing explanation about this pathogenesis of PVNS is that a mitochondrial abnormality exists primarily in PVNS which is independent of the precipitation of haemosiderin. In that case, the overload of iron deposits in the cytoplasm and mitochondria could induce free radicals. However, abnormal mitochondria would be responsible for supplying a key reactant, humanin, to prevent oxidative damage until they are autophagocytosed within the siderosome, resulting in cell survival. In accordance with this view, analysis of isolated cells has enabled us to describe here for the first time the feature of mitochondria containing haemosiderin, which were autophagocytosed and degenerating within the siderosome, in addition to many mitochondria without haemosiderin scattered around the cytoplasm.

Taken together, our findings lead us to a simple interpretation that the possible function of humanin located within the mitochondria in PVNS synovial cells may be to serve as a rescue factor from excessive iron damage and consequent organelle breakdown in the cytoplasm and cell death. However, Hashimoto et al have shown that cell death is only supported by the secreted humanin peptide, ${ }^{29}$ and the function of the peptide located intracellularly is still unclear. Although future studies are required to investigate the function of humanin within the cytoplasm, our data suggest that humanin is involved in the iron depositing pathology of PVNS. In conclusion, our results suggest that the humanin peptide is highly expressed in the synovial cells from diffusetype PVNS and may play a part in the pathology of PVNS.

\section{ACKNOWLEDGEMENTS}

We thank A Tsuchiya MD and S Tsuyama MD for their professional advice.

\footnotetext{
Authors' affiliations

K liiri, H Sakakima, Course of Physiotherapy, School of Health Science, Faculty of Medicine, Kagoshima University, Kagoshima, Japan K liiri, M B Goldring, Beth Israel Deaconess Medical Center, New England Baptist Bone and Joint Institute, Boston, MA, USA H Tsuruga, T Matsuyama, Immunology and Medical Zoology, Graduate School of Medicine, Kagoshima University, Kagoshima, Japan
}

N Taniguchi, K Shimoonoda, S Komiya, Department of NeuroMusculoskeletal Disorder, Kagoshima University Graduate School of Medicine and Dentistry, Kagoshima University, Kagoshima, Japan K Tomita, H J Majima, Department of Oncology, Kagoshima University Graduate School of Medicine and Dental Science, Kagoshima, Japan

\section{REFERENCES}

1 Jaffe HL, Lightenstein L, Sutro CJ. Pigmented villonodular synivitis, bursitis and tenosynovitis. Arch Pathol 1941;31:731-65.

2 Dorwart RH, Genant HK, Johnston WH, Morris JM. Pigmented villonodular synovitis of synovial joints: clinical, pathologic, and radiologic features. AJR Am J Roentgenol 1984;143:877-85.

3 Darling JM, Glimcher LH, Shortkroff S, Albano B, Gravallese EM. Expression of metalloproteinases in pigmented villonodular synovitis. Hum Pathol 1994;25:825-30

4 Gehweiler JA, Wilson JW. Diffuse biarticular pigmented villonodular synovitis. Radiology 1969:93:845-51.

5 Crosby EM, Inglis A, Bullough PG. Mulitple joint involvement with pigmented villonodular synovitis. Radiology 1977;122:671-2.

6 Wagner ML, Spjut HJ, Dutton RV, Glassman AL, Askew JB. Polyarticular pigmented villonudular synovitis. AJR Am J Roentgenol 1981;136:821-3.

7 Byers PD, Cotton RE, Deacon OW, Lowy M, Newman PH, Sissons HA, et al. The diagnosis and treatment of pigmented villonodular synovitis. J Bone Joint Surg Br 1968;50:290-305.

8 Jozsa L. Immunohistochemical characterization of pigmented villonodular synovitis. Zentralbl Pathol 1992;138:119-23.

9 O'Connell JX, Fanburg JC, Rosenberg AE. Giant cell tumor of tendon sheath and pigmented villonodular synovitis. Immunophenotype suggests a synovial cell origin. Hum Pathol 1995;26:771-5.

10 Darling JM, Goldring SR, Harada Y, Handel ML, Glowacki J, Gravallese EM. Multinuclear cells in pigmented villonodular synovitis and and giant cell tumor of tendon sheath express features of osteoclasts. Am J Pathol 1997:150:1383-92.

11 Young JM, Hudacek AG. Experimental production of pigmented villonodular synovitis in dogs. Am J Pathol 1954;30:799-811.

12 Sigh R, Grewal DS, Chakravarti RN. Experimental production of pigmented villonodular synovitis in the knee and ankle joints of rhesus monkey. J Pathol 1969:98:137-42.

13 Somerhausen NSA, Fletcher CDM. Diffuse-type giant cell tumor. Clinicopathologic and immunohistochemical analysis of 50 cases with extraarticular disease. Am J Surg Pathol 2000;24:479-92.

14 Abdul-Karim FW, El-Naggar AK, Joyce MJ, Makley JT, Carter JR. Diffuse and localized tenosynovial giant tumor and pigmented villonodular synovitis: a clinicopathological and flow cytometric DNA analysis. Hum Pathol 1992;23:729-35.

15 Fletcher JA, Henkle C, Atkins L, Rosenberg AE, Morton C. Trisomy 5 and trisomy 7 are nonrandom aberrations in pigmented villonodular synovitis: confirmation of trisomy 7 in uncultured cells. Genes Chromosomes cancer 1992;4:264-6.

16 Schumacher HR, Lotke P, Athreya B, Rothfuss S. Pigmented villonodular synovitis: light and electron microscopic studies. Semin Arthritis Rheum 1982; 12:32-43.

17 Ghadially FN, Lalonde J-M A, Dick CE. Ultrastructure of pigmented villonodular synovitis. J Pathol 1978;127:19-27.

18 Wyllie JC. Stromal cell reaction of pigmented villonodular synovitis: an electron microscopic study. Arthritis Rheum 1969;12:205-14.

19 Maximov V, Martynenko A, Hunsmann G, Tarantul V. Mitochondrial 16S rRNA gene encodes a functional peptide, a potential drug for Alzheimer's disease and target for cancer therapy. Med Hypotheses 2002;59:670-3.

20 Guo B, Zhai D, Cabezas E, Welsh K, Niourain S, Tatterthwait A, et al. Humanin peptide suppresses apoptosis by interfering with Bax activation. Nature. 2003;423: 456-61, Epub 4 May, 2003.

21 Chomczynski P, Sacchi N. Single-step method of RNA isolation by acid guanidinium thiocyanate-phenol-chlorform extraction. Anal Biochem 1987; 162:156-9

22 Majima JH, Oberley TD, Fukukawa K, Mattson MP, Yen HC, Szweda Ll, et al. Prevention of mitochondrial injury by manganese superoxide dismutase reveals a primary mechanism for alkaline-induced cell death. J Biol Chem 1998;273:8217-24

23 Motoori S, Majima HJ, Ebara M, Kato H, Hirai F, Kakinuma S, et al. Overexpression of mitochondrial manganese superoxide dismutase protects against radiation-induced cell death in the human hepatocellular carcinoma cell line, HLE. Cancer Res 2001;61:5382-8.

24 Peng G, Taylor JD, Tchen T. Increased mitochondrial activites in pigmented (melanized) fish cells and nucleotide sequence of mitochondrial large rRNA. Biochem Biophys Res Commun 1992;189:445-9.

25 Baserga SJ, Linnenbach AJ, Malcolm S. Polyadenylation of a human mitochondrial ribosomal RNA transcript detected by molecular cloning. Gene 1985;35:305-12.

26 Tarantul V, Nikolaev A, Hannig H. Detection of abundantly transcribed genes and gene translocation in human immunodeficiency virus-associated nonHodgkin's lymphoma. Neoplasia 2001;3:132-42.

27 Penta J, Johnson FM, Wachsman JT, Copeland WC. Mitochondrial DNA in human malignancy. Mutat Res 2001;488:119-33.

28 Hashimoto Y, Niikura T, Tajima H, Yasukawa T, Sudo H, Ito Y, et al. A rescue factor abolishing neural cell death by a wide spectrum of familial Alzheimer's disease. Proc Natl Acad Sci USA 2001;98:6336-41. 
29 Hashimoto $Y$, Ito $Y$, Niikura T. Mechanism of neuroprotection by a novel rescue factor humanin from Swedish mutant amyloid precursor protein. Biochem Biophy Res Commun 2001;283:460-8.

30 Yu W, Sanders BG, Kline K. RRR-alpha-tocopheryl succinate-induced apoptosis of human breast cancer cells involved bax translocation to mitochondria. Cancer Res 2003;63:2483-91.

31 Nakazawa Y, Kamijo T, Koike K, Noda T. ARF tumor suppressor induces mitochondria-dependent apoptosis by modulation of mitochondrial $\mathrm{Bcl}-2$ family proteins. J Biol Chem. 2003;278: 27888-95, Epub 9 May, 2003.

32 Muirden KD. The anemia of rheumatoid arthritis: the significance of iron deposits in the synovial membrane. Aust Ann Med 1970;2:97-104.

33 Brunk UT, Terman A. The mitochondrial-lysosomal axis theory of aging: accumulation of damaged mitochondria as a result of imperfect autophagocytosis. Eur J Biochem 2002;269:1996-2002.

34 Morris CJ, Wainwright AC, Steven MM. The nature of iron deposits in haemophilic synovitis - an immunohistochemical ultrastructural and x-ray microanalytical study. Virchows Arch A Pathol Anat Histopathol 1984;404:75-85.

35 Docken WP. Pigmented villonodular synovitis: a review with illustrative case reports. Semin Arthritis Rheum 1979;9:1-22.
36 Wixom RL, Prutkin L, Munro HN. Hemosiderin: nature, formation, and significance. Intl Rev Exp Pathol 1980;22:193-225.

37 Chamberlain MA, Petts V, Gollins E. Transport of intravenously injected ferritin across the guinea-pig synovium. Ann Rheum Dis 1972;31:493-9.

38 McCord JM, Roy RS. The pathophysiology of superoxide; roles in inflammation and ischaemia. Can J Physiol Pharmacol 1982;60:1346-52.

39 Halliwell B, Gutteridge JM. Oxygen toxicity, oxygen radicals, transition metals and disease. Biochem J 1984;219:1-4.

40 Panduri V, Weitzman SA, Chandel N, Kamp DW. The mitochondriaregulated death pathway mediates asbestos-induced alveolar epithelial cell apoptosis. Am J Respir Cell Mol Biol 2003;28:241-8.

41 Gutteridge JM, Halliwell B, Treffry A, Harrison PM, Blake DR. Effect of ferritin containing fractions with different iron loading on lipid peroxidation. Biochem J 1983;209:557-60.

42 Crichton RR. Interreaction between iron metabolism and oxygen activation. In: Oxygen free radicals and tissue damage. Amsterdam: Excerpta Medica, 1979:57-76.

43 Morris CJ, Blake DR, Wainwright AC, Steven MM. Relationship between iron deposits and tissue damage in the synovium: an ultrastructural study. Ann Rheum Dis 1986;45:21-6. 